\title{
Особенности состава эклогитов Берген Аркс (Норвегия)
}

\author{
Салимгараева Л.И. ${ }^{1}$, Березин А.В. ${ }^{2,3}$, Скублов С.Г. ${ }^{2,1}$ \\ ${ }^{1}$ Санкт-Петербургский горный университет, Санкт-Петербург, fluoritecaf2@mail.ru \\ ${ }^{2}$ Институт геологии и геохронологии докембрия РAH, Санкт-Петербург, skublov@yandex.ru \\ ${ }^{3}$ Санкт-Петербургский государственный университет, Санкт-Петербург, berezin-geo@yandex.ru
}

Аннотация. В работе приводятся результаты исследования химического и минерального составов эклогитов и их протолитов комплекса Берген Аркс. Полевые работы проводились на острове Холсной на юго-западе Норвегии. Эклогиты приурочены к тектонически ослабленным зонам. Процессы эклогитизации не приводят к значительному изменению химического состава пород. Происходит перераспределение главных и редких компонентов на минеральном уровне, что продемонстрировано на примере граната.

Ключевые слова: эклогиты, комплекс Берген Аркс, метаморфизм, локальные методы, гранаты, редкоземельные элементы.

\section{Features of eclogite of the Bergen Arcs (Norway) composition}

\author{
Salimgaraeva L.I. ${ }^{1}$, Berezin A.V. ${ }^{2,3}$, Skublov S.G. ${ }^{2,1}$ \\ ${ }^{1}$ St.-Petersburg mining university,St.-Petersburg, fluoritecaf2@mail.ru \\ ${ }^{2}$ Institute of Precambrian geology and geochronology RAS, St.-Petersburg, skublov@yandex.ru \\ ${ }^{3}$ St.-Petersburg university,St.-Petersburg, berezin-geo@yandex.ru
}

\begin{abstract}
This paper reviews results of studying chemical and mineralogical composition of eclogites and their protolith from the Bergen Arcs complex. Field works have been carried out on Holsnøy Island (SW Norway). Eclogites are formed in shear zones. Eclogitization processes do not change chemical composition of protolith. Redistribution of the main and rare components occurs at the mineral level and is exemplified by garnet.
\end{abstract}

Key words: eclogites, Bergen Arcs complex, metamorphism, local methods, garnets, rare-earth elements.

Полиметаморфический комплекс Берген Аркс, которому посвящена данная работа, считается отличным полигоном для изучения метаморфических процессов, происходящих в основании континентальной коры в коллизионных зонах, поскольку предполагается (исходя из оценок Р-Т условий и минеральных ассоциаций), что породы комплекса были погребены на глубину, соответствующую современным корневым зонам коры, развитым под современными Альпами и Гималаями (Austrheim, 2013). Несмотря на то, что этому объекту посвящено огромное количество работ, остаются некоторые нерешенные вопросы геохимии пород и минералов комплекса, в частности, например, распределение редких и редкоземельных элементов в породообразующих минералах.

Комплекс Берген Аркс является частью каледонского орогена на западе Норвегии, сформированного в результате коллизии Лаврентии и Балтии в позднем ордовике - раннем девоне. В структурном плане комплекс представлен серией аркообразных покровов, надвинутых на породы Западного гнейсового района. Контакт между комплексами тектонический, с развитием зоны пластической деформации.

Комплекс представлен телом анортозитов, метаморфизованных в гранулитовой фации в неопротерозое. Это тело интерпретируется как выведенная на поверхность пластина нижней континентальной коры и предполагается, что оно было сформировано как расслоенная интрузия, сложенная основными породами от анортозитов до габбро-анортозитов и норитов (Austrheim, 1987). Процессы эклогитизации уже каледонского возраста проявлены в так называемых shear-зонах различной мощности (рис. 2).

\section{Исходный материал и методы исследования}

Образцы были отобраны в ходе полевых работ в 2018 году на острове Холсной (рис. 1), находящемся на юго-западе Норвегии. Химический состав пород был определен методом ICP-MS на 


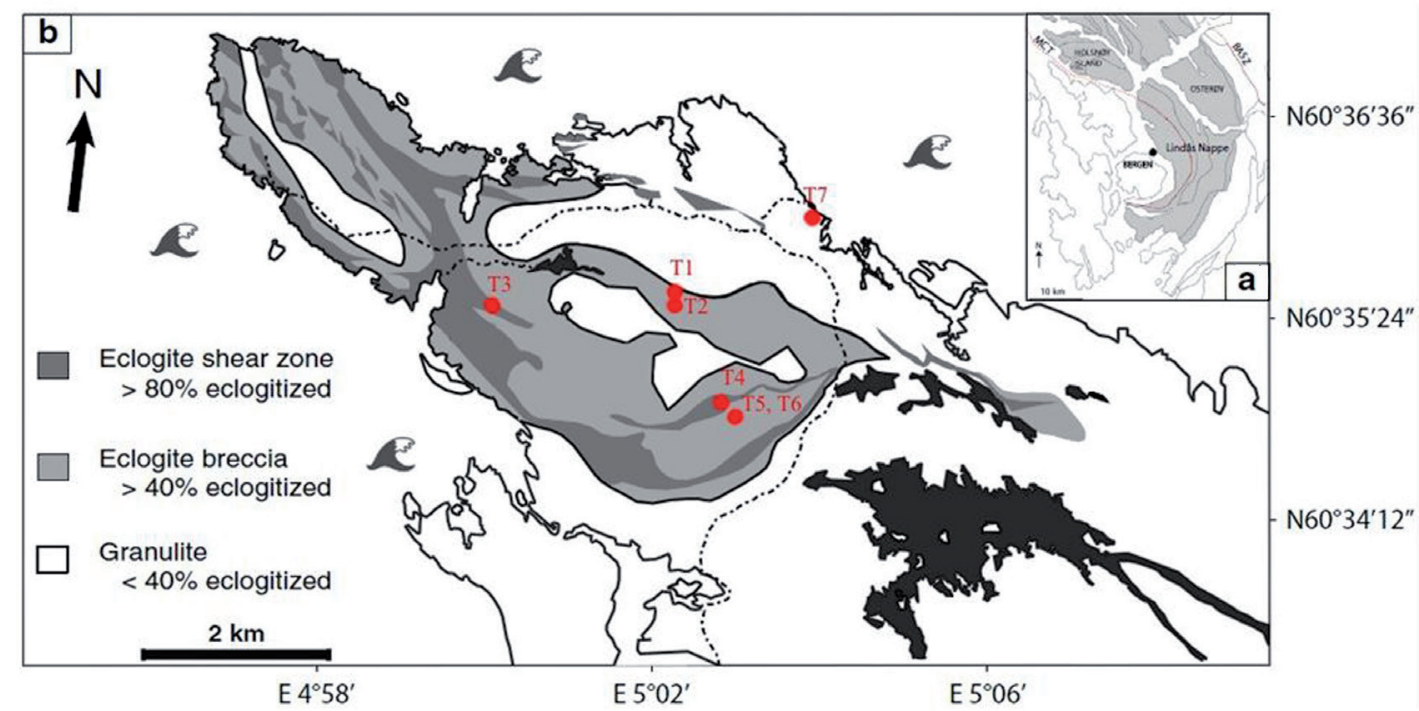

Рис. 1. a - положение острова Холсной относительно Бергена на западе Норвегии; b - схема геологического строения северной части острова Холсной (Holsnøy) по (Austrheim et al., 1996). Красными точками обозначены места отбора проб.

Fig. 1. a - Location of the Holsnøy Island relative to Bergen in western Norway; b - Geological map of the northern Holsnøy Island modified after Austrheim et al. (1996). Red labels mark sampling points.

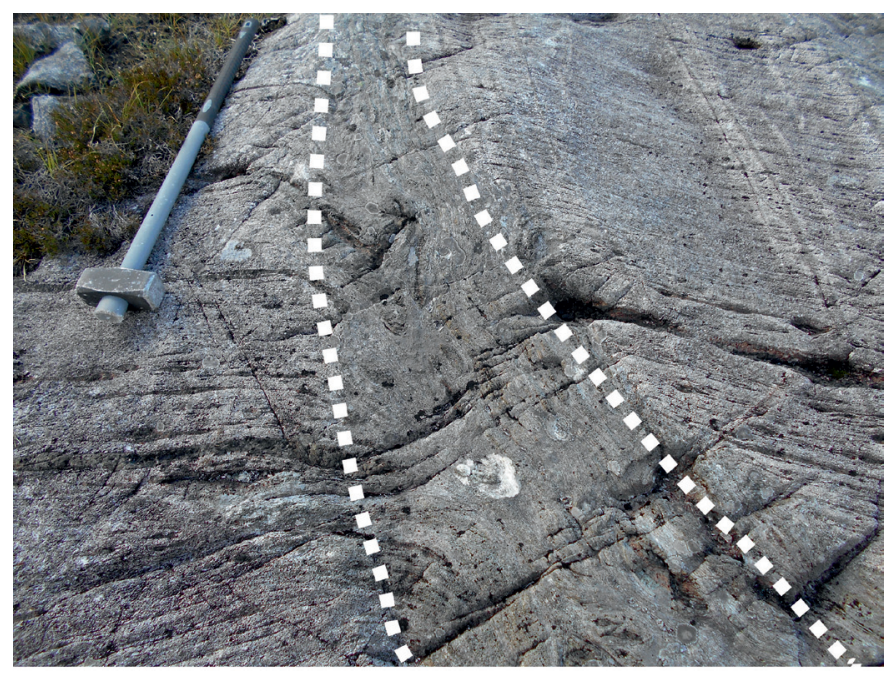

Рис. 2. Зона эклогитизации в гранулитах.

Fig. 2. Eclogitization zone in granulites.

приборе ELAN-6100 DRC (ВСЕГЕИ). Сoдержание редких и редкоземельных элементов в минералах было определено на ионном микрозонде Cameca-IMS-4f в ЯФ ФТИАН после предварительного исследования методом SEM-EDS (JEOL JSM6510LA с энергодисперсионной приставкой JED-2200) в ИГГД РАН.

\section{Результаты}

В процессе эклогитизации не происходит изменений состава гранулитов по главным компонентам: гранулиты и эклогиты лежат в одном поле на AFMдиаграмме, соответствующим щелочноизвестковой серии (рис. 3 а). В целом, эклогиты более обогащены редкоземельными элементами, чем гранулиты, но не более чем на один порядок. Поля содержаний REE этих пород перекрываются, формы спектров не меняются (рис. 3 б), то есть изменения в редкоземельном составе пород незначительны.

Основными породообразующими минералами гранулитов являются гранаты, плагиоклазы и клинопироксены. Гранаты образуют порфиробласты размером до 2 мм, плагиоклаз слагает основной матрикс. Клинопироксен формирует секущие метаанортозит прожилки. Кроме этих минералов наблюдаются в небольшом количестве: биотит, флогопит, силлиманит, клиноцоизит, ильменит, шпинель.

В эклогитах также фиксируется наложенный регрессивный метаморфизм амфиболитовой фации, выражающийся в появлении амфибола. Кроме того, темноокрашенные слюды сменяются мусковитом и наблюдается распространение клинопироксен-плагиоклазовых симплектитов. Гранат визуально не изменяется, а также как и в гранулитах, образует порфиробласты. 

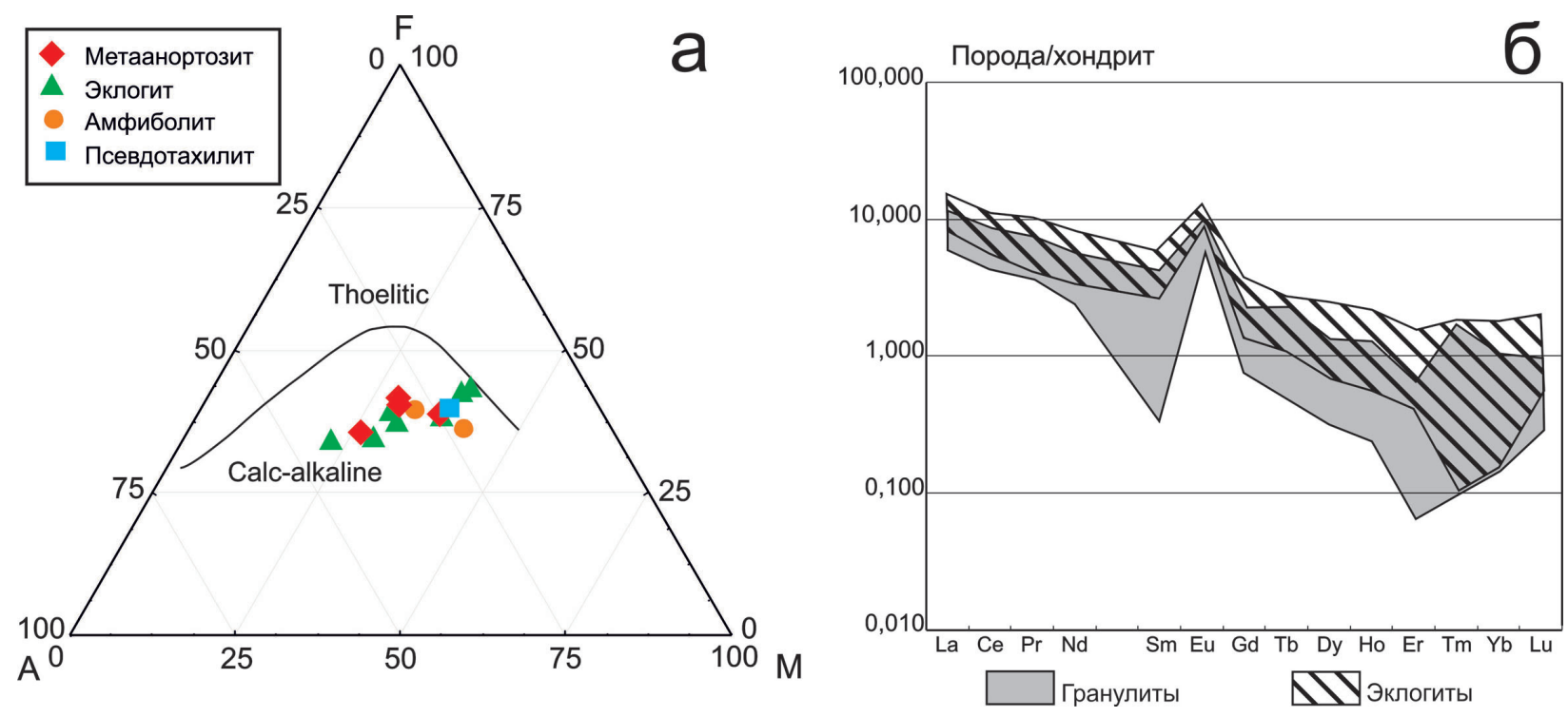

Рис. 3. a - AFM-диаграмма; б - спектры распределения REE в породах. Содержание REE нормировано на состав хондрита CI по (McDonough, Sun, 1995).

Fig. 3. a - AFM-diagram; b - REE distribution spectra different rocks. Composition of REE is chondrite-normalized after (McDonough, Sun, 1995).

Гранаты - являются сквозными минералами в исследуемых породах и представляют в данном случае наибольший интерес.

Гранаты из гранулитов не проявляют зональности (рис. 4 a), и их состав практически постоянен. Гранаты из эклогитов же имеют каймы (рис. 4 б), резко отличающиеся по составу как главных, так и редких компонентов. Центральные части гранатов из эклогитов соответствуют по своему составу гранатам гранулитов (рис. 5 a).

Каймы гранатов из эклогитов отличаются повышенным содержанием альмандинового и спессартинового миналов и пониженным - пиропового, что качественно указывает на понижение температуры метаморфизма. Составы центральной и краевой (каймы) частей гранат достаточно контрастны, что говорит о резкой смене параметров метаморфизма и интенсивном воздействии флюида в процессе перекристаллизации граната (Pollok et al., 2008). Кроме того, контрастность состава краевых зон гранатов по редким элементам свидетельствует об относительно кратковременном
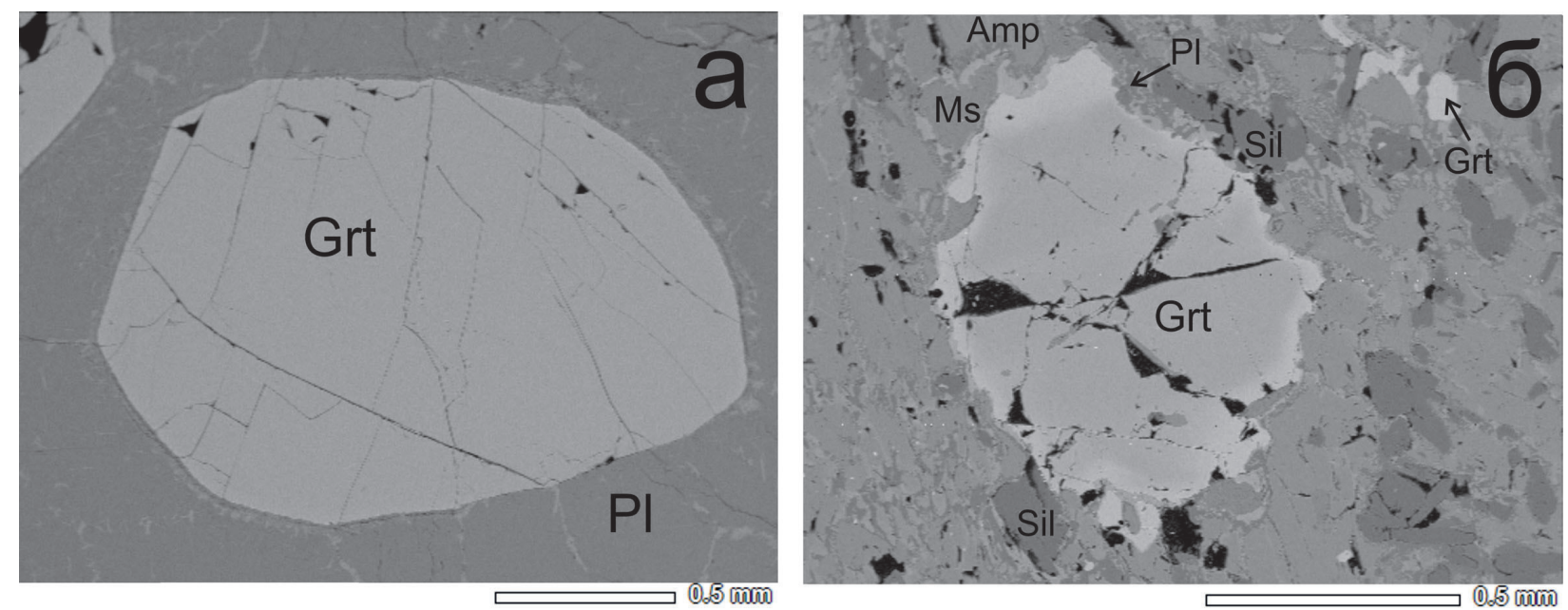

Рис. 4. BSE-изображение граната из: а - гранулита; б - эклогита.

Fig. 4. Back-scattered electron image of a garnet from: $a$ - granulite; $b$ - eclogite. 
Табл. 1. Представительные анализы основных породообразующих минералов.

Table 1. Representative analysis of the main rock-forming minerals.

\begin{tabular}{|c|c|c|c|c|c|c|c|c|}
\hline & \multicolumn{4}{|c|}{ Минералы гранулитов } & \multicolumn{4}{|c|}{ Минералы эклогитов } \\
\hline & \multicolumn{2}{|c|}{ Гранат } & \multirow{2}{*}{ Клинопироксен } & \multirow{2}{*}{ Плагиоклаз } & \multicolumn{2}{|c|}{ Гранат } & \multirow[t]{2}{*}{ Амфибол } & \multirow{2}{*}{$\begin{array}{c}\text { Симплектитовый } \\
\text { клинопироксен }\end{array}$} \\
\hline & core & rim & & & core & rim & & \\
\hline Обр. & 1801 & 1801 & 1801 & 1801 & 1802 & 1802 & 1802 & 1807 \\
\hline № точки & 1 & 3 & 6 & 4 & 38 & 36 & 16 & 33 \\
\hline \multicolumn{9}{|c|}{ Содержание, \% } \\
\hline $\mathrm{SiO}_{2}$ & 40.71 & 40.38 & 50.58 & 59.31 & 40.68 & 39.13 & 56.50 & 54.32 \\
\hline $\mathrm{TiO}_{2}$ & - & - & 0.68 & - & - & - & - & 0.30 \\
\hline $\mathrm{Al}_{2} \mathrm{O}_{3}$ & 22.92 & 22.49 & 9.12 & 26.48 & 22.82 & 21.45 & 14.43 & 6.59 \\
\hline $\mathrm{FeO}$ & 17.15 & 17.52 & 6.49 & - & 16.33 & 22.68 & 5.45 & 4.55 \\
\hline $\mathrm{MnO}$ & 0.20 & 0.23 & 0.03 & - & - & 1.06 & 0.16 & 0.08 \\
\hline $\mathrm{MgO}$ & 11.76 & 12.26 & 10.31 & - & 12.41 & 5.87 & 5.82 & 11.07 \\
\hline $\mathrm{CaO}$ & 7.27 & 7.12 & 21.12 & 8.00 & 7.77 & 9.81 & 11.02 & 19.66 \\
\hline $\mathrm{Na}_{2} \mathrm{O}$ & - & - & 1.66 & 5.91 & - & - & 6.61 & 3.42 \\
\hline $\mathrm{K}_{2} \mathrm{O}$ & - & - & - & 0.30 & - & - & - & - \\
\hline $\mathrm{Cl}$ & - & - & - & - & - & - & - & - \\
\hline Сумма & 100.01 & 100.00 & 99.99 & 100.00 & 100.01 & 100.00 & 99.99 & 99.99 \\
\hline \multicolumn{9}{|c|}{ Содержание, ppm } \\
\hline $\mathrm{La}$ & 0.030 & 0.036 & 3.77 & 2.86 & b.d.l. & 0.006 & 0.004 & \\
\hline $\mathrm{Ce}$ & 0.254 & 0.199 & 14.8 & 4.08 & 0.050 & 0.013 & 0.005 & \\
\hline $\operatorname{Pr}$ & 0.102 & 0.058 & 2.39 & 0.313 & 0.037 & 0.003 & 0.004 & \\
\hline $\mathrm{Nd}$ & 1.27 & 0.986 & 12.0 & 0.787 & 0.768 & 0.022 & 0.031 & \\
\hline $\mathrm{Sm}$ & 1.20 & 0.997 & 1.93 & 0.065 & 0.657 & 0.044 & 0.025 & \\
\hline $\mathrm{Eu}$ & 1.19 & 1.08 & 1.38 & 0.811 & 1.23 & 0.233 & 0.025 & \\
\hline $\mathrm{Gd}$ & 1.67 & 1.53 & 1.76 & 0.045 & 0.516 & 0.224 & 0.013 & \\
\hline $\mathrm{Tb}$ & 0.286 & 0.293 & 0.333 & 0.021 & 0.095 & 0.102 & 0.004 & \\
\hline Dy & 1.22 & 1.67 & 0.472 & 0.119 & 0.351 & 1.24 & 0.029 & \\
\hline Ho & 0.225 & 0.290 & 0.103 & 0.113 & 0.050 & 0.483 & 0.004 & \\
\hline $\mathrm{Er}$ & 0.597 & 0.814 & 0.147 & 0.122 & 0.222 & 2.52 & b.d.l. & \\
\hline $\mathrm{Yb}$ & 0.490 & 0.917 & b.d.l. & 0.030 & 0.213 & 5.57 & 0.029 & \\
\hline $\mathrm{Lu}$ & 0.086 & 0.169 & 0.028 & 0.005 & 0.027 & 0.817 & 0.004 & \\
\hline Сумма & 8.62 & 9.04 & 39.1 & 9.36 & 4.21 & 11.3 & 0.176 & \\
\hline
\end{tabular}

проявлении эклогитового метаморфизма. Спектры REE в каймах гранатов (рис. 5 б) соответствуют типичным спектрам эклогитовых гранатов (Скублов, 2005).

Клинопироксены гранулитов соответствуют по своему составу диопсиду, а симплектитовый клинопироксен эклогитов - омфациту (рис. 6 a). 

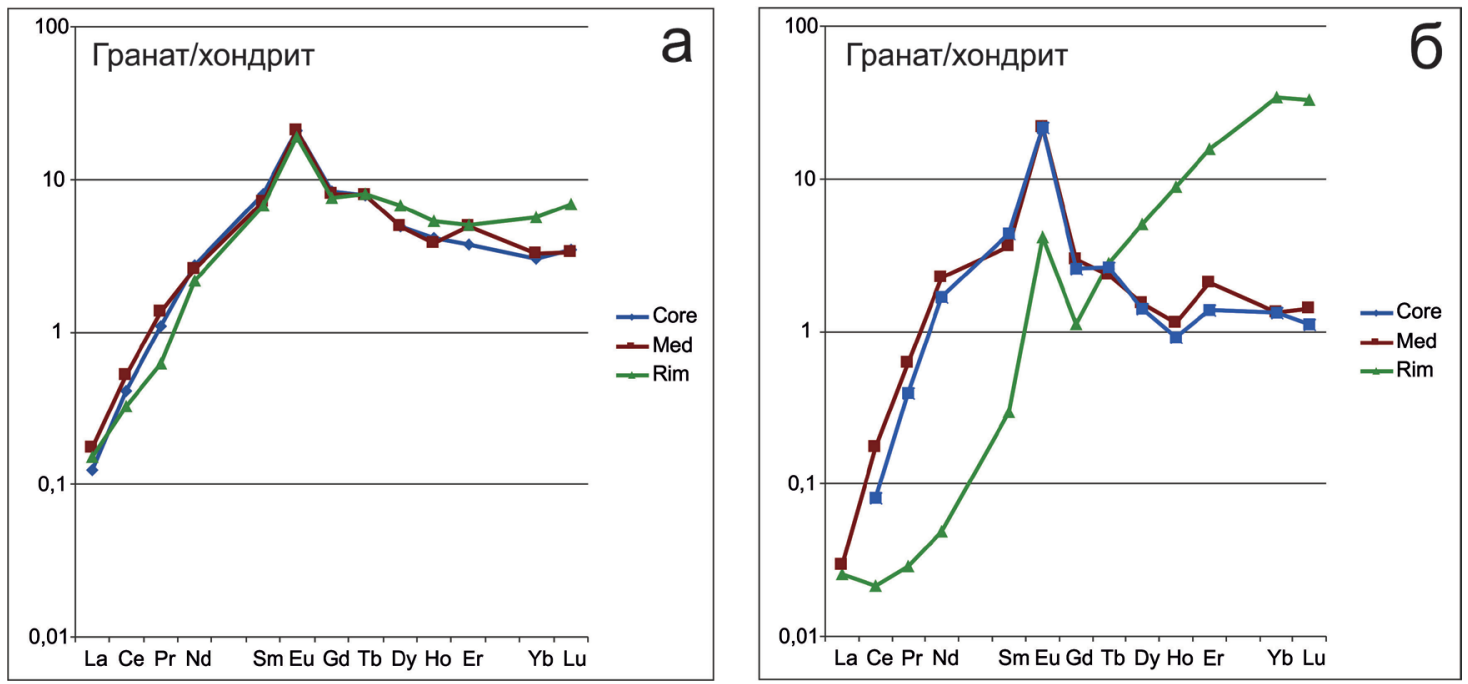

Рис. 5. Спектры распределения REE в гранатах из: а - гранулита; б - эклогита. Содержание REE нормировано на состав хондрита CI по (McDonough W.F., Sun S.S., 1995).

Fig. 5. REE distribution spectra in garnets from: a - granulites; b - eclogites. Composition of REE is chondritenormalized after (McDonough W.F., Sun S.S., 1995).
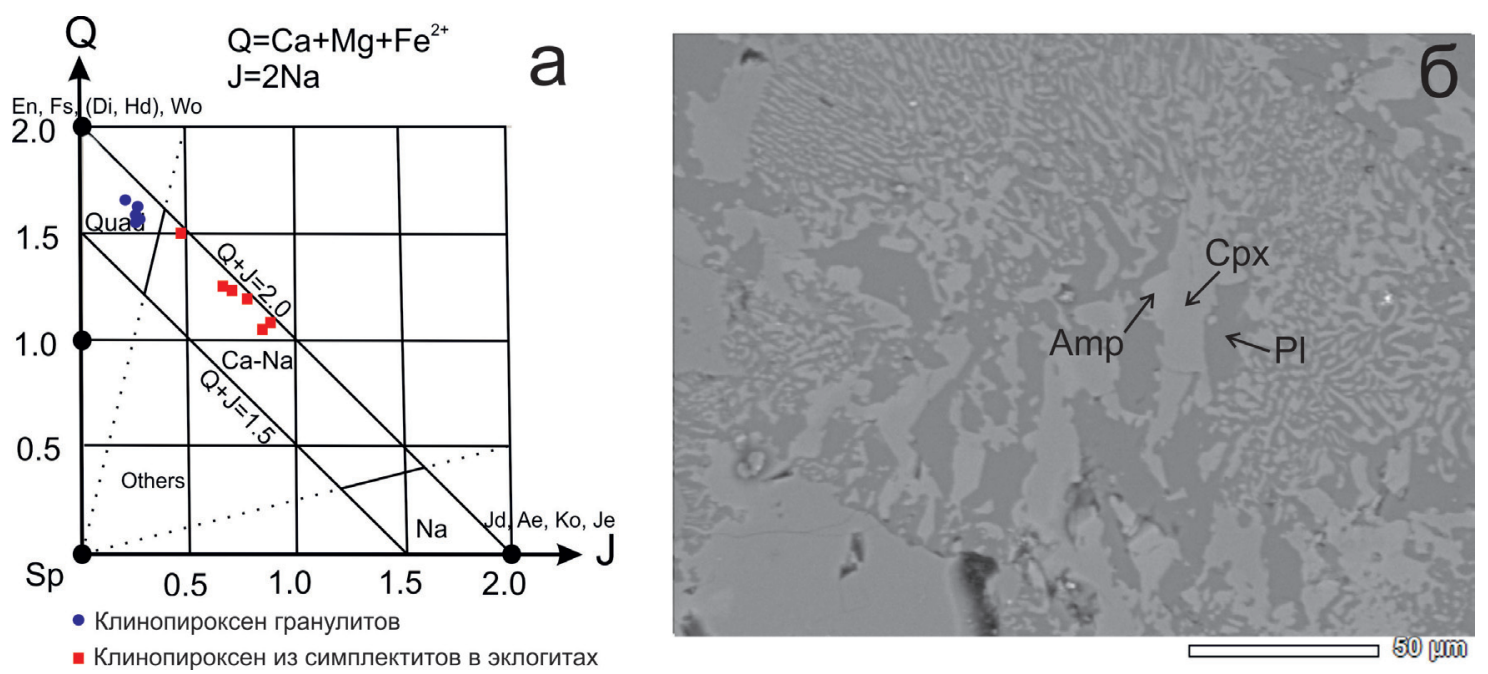

Рис. 6. а - Q-J диаграмма (Morimoto et al., 1988) для клинопироксенов; б - симплектиты в эклогитах.

Fig. 6. a-Q-J diagram (Morimoto et al., 1988) for clinopyroxenes; b-symplectites in eclogites.

\section{Литература}

1. Скублов С.Г. Геохимия редкоземельных элементов в породообразующих метаморфических минералах. СПб. Изд-во: Наука. 2005. 147 с.

2. Austrheim H. Fluid and deformation induced metamorphic processes around Moho beneath continent collision zones: Examples from the exposed root zone of the Caledonian mountain belt, W-Norway // Tectonophysics. 2013. V. 609. P. 620-635.

3. Austrheim H., Erambert M., Boundy T.M. Garnets recording deep crustal earthquakes // Earth and Planetary Science Letters. 1996. V. 139(1). P. 223-238.

4. Boundy T.M., Mezger K., Essene E.J. Temporal and tectonic evolution of the granulite - eclogite association from the Bergen Arc, western Norway // Tectonophysics. 1997. V. 39. P. 159-178.

5. McDonough W.F., Sun S.S. The composition of the Earth // Chemical Geology. 1995. V. 120. P. $223-253$.

6. Morimoto N., Fabries J., Ferguson A.K., Ginzburg I.V., Ross M., Seifert F.A., Zussman J., Aoki K., Gottardi G. Nomenclature of pyroxenes // American Mineralogist. 1988. V. 73. P. 1123-1133.

7. Pollok K., Lloyd G.E., Austrheim H., Putnis A. Complex replacement patterns in garnets from Bergen Arcs eclogites: a combined EBSD and analytical TEM study // Chemie der Erde-Geochemistry. 2008. V. 68. P. 177-191. 